\title{
Conservation of The
}

\section{Chiara Cusolito* Laura Di Marino** Alessia Silvetti ${ }^{* \star *}$}

\section{Abstract}

The conservation of Pertev Pasha Mosque should not be considered as a mere practice of static or architectural restoration but as an integrated project to implement all those principles adopted by the "Conservation of Historic Towns Chart" (ICOMOS, 1986-87).

Promotion of the urban fabric therefore, represents the necessary correlation of conservation such as the research into appropriate functions expressing social needs and an active involvement of the factors necessary for its protection. This active involvement must be necessarily confronted with the peculiarity of the mosque, fostering its knowledge, the compatible proposal of use and a plan of intervention.

On the basis of the requirements above mentioned, the study is, in principle, developed through the acquisition and re-elaboration of the data referring to a macro area, i.e. Turkey considered as a nation. Passing through the analysis of the province and the city of Izmit, a micro-area that will be the focus of the analysis, has been identified.
Keywords: Mosque; Mimar Sinan; diagnostics; minimum intervention; integrated conservation; cultural heritage.

*Construction engineer, graduate of Polytechnic of Milan, Italy.

E-mail: chiara.cusolito@mail.polimi.it Orcid ID: http://orcid.org/0000-0002-50755271

**Tutor at the School of Building Architecture and Engineering, Polytechnic of Milan, Italy.

E-mail: laura.dimarino@mail.polimi.it Orcid ID: http://orcid.org/0000-0002-46143408

***Adjunct professor at the School of Building Architecture and Engineering, Polytechnic of Milan, Italy.

E-mail: alessia.silvetti@polimi.it Orcid ID: http://orcid.org/0000-0002-42836274 
The project provides integrations suitable to increase the background value, further emphasizing the whole Pertev Pasha complex, respecting the needs of territorial enhancement as well as those of the local community and those related to the cultural heritage and recovery.

The proposed actions will be divided into the following areas:

- urban

- functional

- punctual

The aim of the study is to suggest a model to conservative restoration that, although limited to a small part of the city, may in some way act as an incubator allowing Izmit, which today is a high-density city divided into two parts by the highway and separated from Its splendid coast, to return in the future, some of the balance and splendor that made it famous when it was called Nicomedia.

\section{INTRODUCTION}

"... the qualities we inherited from the past can become a discipline for change today... A town's past, its present and its future must combine to create a recognizable unit, so that its growth can be seen and felt to be continuous."-

(W.Roy, 1969)

The "Idea (s) Izmit" workshop was organized in Izmit, Kocaeli,Turkey, from 7 to 11 September 2015, on the basis of the programs of collaboration between the Polytechnic of Milan, Kocaeli University, Turkey, and Ball State University. The following professors worked on the project: Elisabetta Rosina, professor of the Polytechnic of Milan, Emre Kishali, professor of Kocaeli University and Jonathan Spodek, professor of Ball State University. Their main objective was the application of nondestructive tests on the structures of the historical Kocaeli mosque (Pertev Pasha) as part of its planned conservation (E.Kishali et al.,2016).

This purpose has been expanded in the subsequent phases in order that the restoration of the Pertev Pasha Mosque was not understood solely as a mere exercise of static and/or a technique of architectural restoration, but also as an opportunity to enhance the cultural heritage of Izmit. 


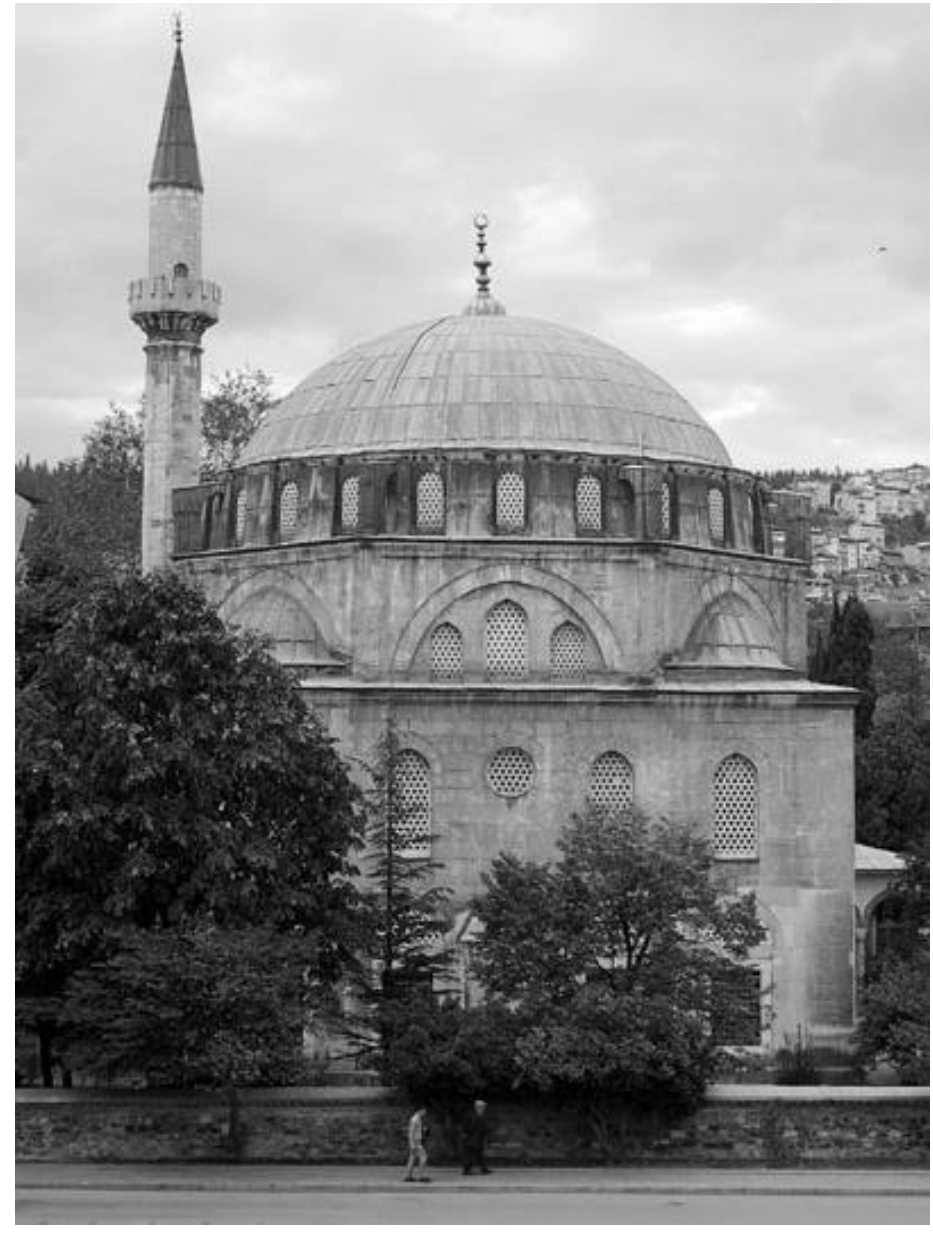

"The concept of a historic monument embraces not only the single architectural work but also the urban or rural setting in which is found the evidence of a particular civilization, a significant development or a historic event. "

(ICOMOS,1964)

The preservation of the mosque must be inserted within the context of the enhancement of the urban fabric, with the search for appropriate functions expressing social needs within an active involvement of the subjects in charge of its protection.

The project, which is based on a multidisciplinary approach, has been divided into the following phases:

- urban analysis, which has been summarized with a SWOT analysis;

- urban enhancement, implemented objectives and strategies that enhance site opportunities and resolve any critical issues encountered, taking into account its citizens.

- investigations into the state of conservation of the mosque;

- conservative restoration project for the mosque based on the principles of conservation or reversibility with minimum intervention.
Figure 1. Pertev Pasha Mosque, arch. Mimar Sinan 
The project, therefore, developed in a hierarchical way, from the urban macroscala of Izmit up to the punctual restoration intervention of the restoration of the mosque, which is a symbol of the identity of Izmit and its citizens.

Therefore, the conservation project is, in effect, an integrated project aimed at ensuring not only the protection of prestigious architectural and environmental buildings, but also inserting the same protection in the most general theme of the remodeling of the contemporary city and the function and precise objective of improving quality of life, with the priority of respect for values and local traditions, not just cultural, historical and architectural ones but also those related to everyday life and current affairs

\section{URBAN REGENERATION}

\section{Historic-critical analysis}

Izmit is a city in the province of Kocaeli in Turkey. It is $40 \mathrm{~km}$ from Istanbul and $100 \mathrm{Km}$ from Ankara and today it is developing along the highway that links these two cities. Its position on the gulf of Goluck has favored the growth of the port since its origins and today Izmit is a very important Turkish commercial center thanks to its numerous industries.

Izmit at the time of ancient Rome was known as Nicomedia. During the Ottoman period, the city developed greatly thanks to the railway which once crossed the center, today the Boulevard, and the port where today the warehouses remain_(J.P. Roux, 2010).

During the First World War Izmit was invaded by Britain in 1918 and then by the Greeks in 1920. At the end of the conflict Izmit became part of the Ottoman Empire. The province of Kocaeli was founded in 1924, immediately after the proclamation of the Turkish Republic.

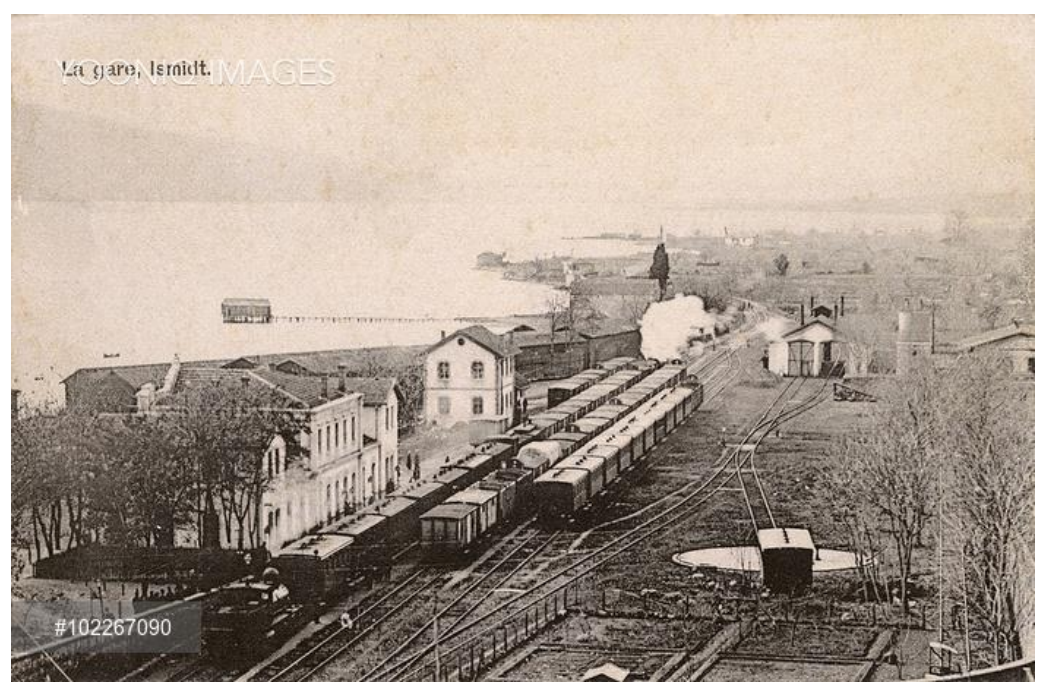


A large part of the architectural heritage of the city was lost due to the various conflicts for the conquest of commercial power, partly by the various natural disasters that occurred in the territory being the earthquake of 1999 .

Nevertheless, Izmit still retains the ruins that bear witness to its glorious past, including the Ottoman buildings, the Public House (1938) which still plays a key role in the life of the city and the ruins of the silk factory and Tobacco Factory which have had great importance in the economic development of the city. Another noteworthy building which demonstrates the approach to restoration in Turkey, diametrically the opposite of the Italian approach is the Fevziye Mosque, also designed by the architect, Mimar Sinan. However it has since collapsed or burned down during various earthquakes and has been rebuilt several times with the same shapes and geometries, representing a "historical false"1 (C. Brandi,2000).

\section{Urban contex Analysis}

Our analysis started in the area of the Pertev Pasha Mosque, based on the data collected in situ and also therefore on our perceptions and live experience, enclosed within a gracious park, where many citizens go in search of tranquility.
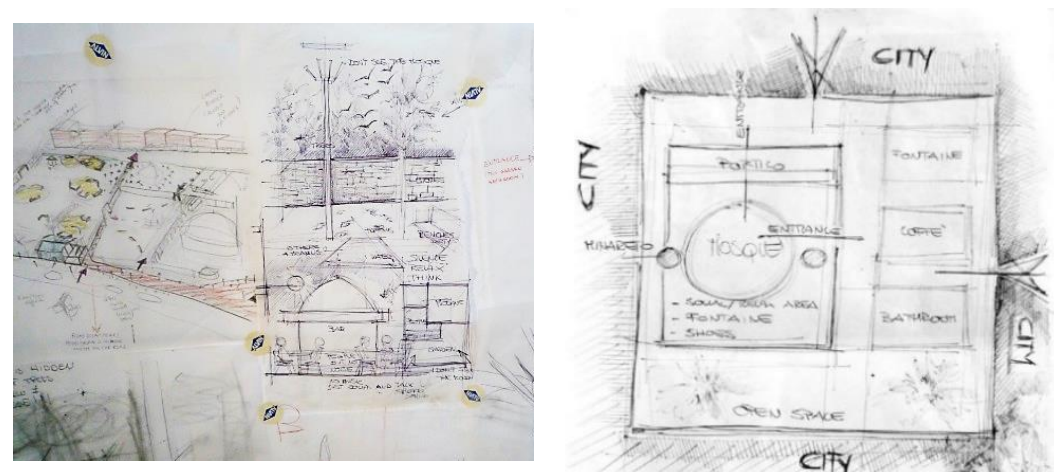

The lot is surrounded by very different environments:

- the long Boulevard Cumhuriyet, a shopping area full of shops and restaurants;

- two parks which contribute to feeding the city's green belt the park of the Tobacco Factory, taking its name from the ruins of the factory after a fire and the park of the Fevziye Cami Mosque, of more recent construction;

- Ottoman-style buildings surviving the devastating Izmit earthquake in 1999;

- the ruins of the Turkish bath and the caravanserai, dating back to the same period of the construction of the mosque;
${ }^{1}$ Re-proposition of an architectural style of a past time, with materials and techniques of the present times.

Figure 3. Perceptive analysis drawings by Alessia Silvetti 
- the tramlines of the historic tram network and the current railway that separates and fragments the historic center of the city separating it from the coast;

- the Mimar Sinan bridge, which connects the shopping area to the coast, contrasting greatly with the mosque. ${ }^{2}$

Figure 3. SWOT analysis circumscribed to the area of relevance of the mosque highlighting the pedestrian flows, the road system and the green areas.

2During the workshop, the aim of the project in order to reduce the contrast between the contemporary architecture and the mosque was accepted by the municipality, which has already carried out the demolition of the coverage of bridge, as shown in the picture below.

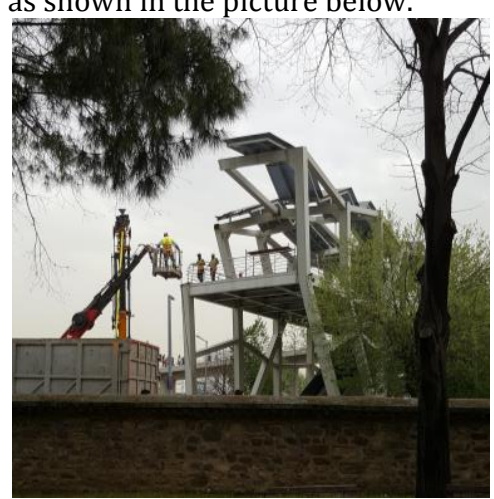

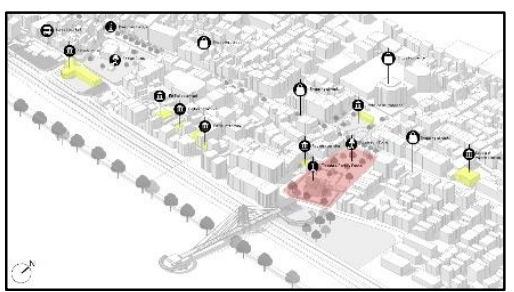
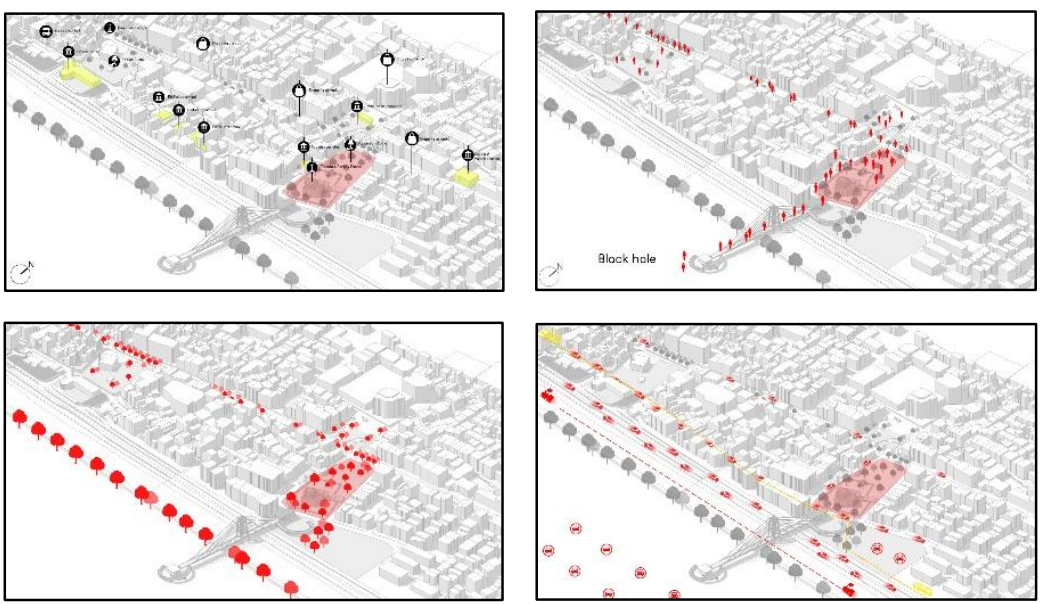

Today Izmit appears to be a heavily built city without a definite urban plan. It is cut into by the highway. The area of the long sea coast is not appreciated very much due to its lack of amenities and cycle paths connecting it to the two adjacent parks (paper factory park and the sports center).

\section{Strategies}

Each community, through the means of its collective memory and knowledge of its past, is responsible for identifying the best way to preserve its heritage. Each element of this heritage is the bearer of many values that the possibility of change.

The proposed urban regeneration aims to transform Izmit from a transit city between Istanbul and Ankara, into a tourist center and commercial exchange recalling the ancient splendor of Nicomedia. The main objective of the project was to unify the urban fabric that is not a present homogeneous and is divided into different areas and to increase the green belt making the areas of commercial, historical, cultural and recreational interest accessible only to pedestrians.

In the urban space devoid of intended use in front of the mosque, the realization of the cultural district that takes the name of "Mosque Factory" has been proposed with the aim of involving active subjects in the protection of cultural heritage.

"The conservation of the architectural heritage should become an integral part of urban and regional planning, instead of being treated as a secondary consideration or one requiring action here and there as has so often been the case in the recent past. A 
permanent dialogue between conservationists and those responsible for planning is thus indispensable."-

(The Declaration of Amsterdam, 1975)

The Factory is a future project dealing with the development and promotion of the territory intervention that tends to enhance and protect architectural and artistic heritage, integrate landscape, tradition and a cultural identity (T. Colletta, 2005).

The design of the Mosque factory enhances the integration between the context and respect for Islamic architectural traditions (W. Curtis, 1989). The themes concerning functionality, structure, technological systems and architectural systems were deepened in the thesis "La Fabbrica della Moschea"3.

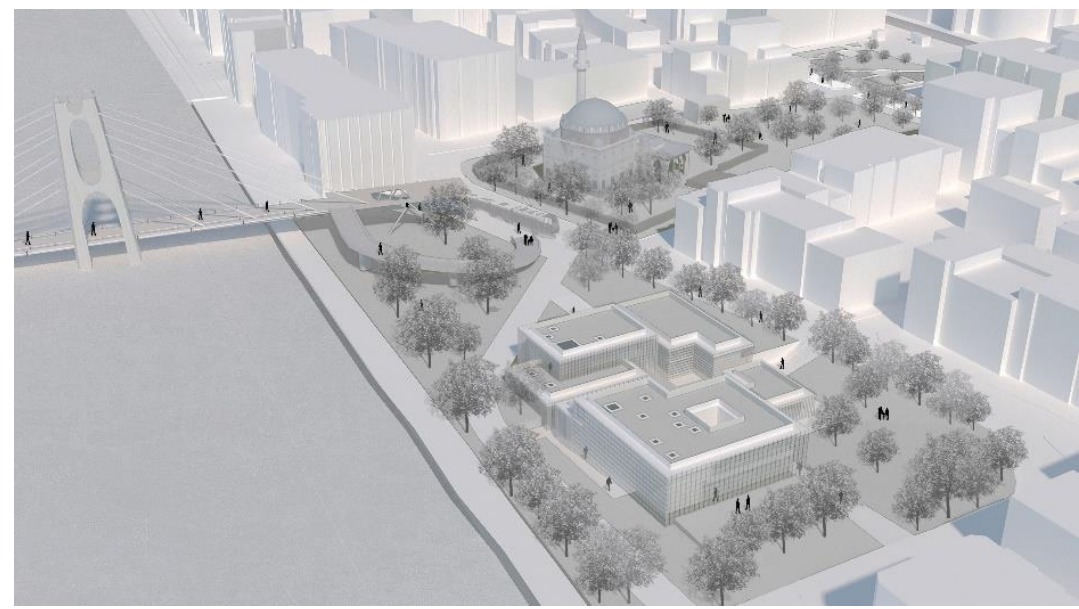

THE CONSERVATION PROJECT OF PERTEV PASHA MOSQUE

The design and construction of the Pertev Pasha Mosque is the work of the architect, Mimar Sinan (1494/1499-1588), the greatest personal architect of the Ottoman Empire from 1538 up to his death (P. De Silvestri, 2012). His experience as a civil and military engineer allowed him to introduce a lot of novelties to religious and residential architecture e.g. the use of innovative techniques for the construction of large domes and the creation of a large monumental complex which not only housed the mosque but also the school, the cemetery, several mausoleums and the refectory (0.Grabar, 1985).

For these reasons, the Mosque is an object of pride for Izmit. In fact, although little known and smaller than the masterpieces of Istanbul, it contains all the technological innovations that were introduced by the architect such as a large dome supported only by the perimeter walls and the absence of internal partitions favoring a large space dedicated to prayer. In fact, the distribution of space reflects the steps of Islamic rite.
${ }^{3}$ Thesis degree in construction architecture and engineering, Polytechnic of Milan. Authors: Chiara Cusolito; Laura Di Marino. Advisor Professor Elisabetta Rosina. http://hdl.handle.net/10589/1346 48

Figure 4. Render: aerial view of the mosque and the "Mosque Factory" 
The first abduction is carried out at a shrine supported by twelve columns with the fountains to wash hands and feet below. The kiosk is located at the center of the sacred enclosure. Under the narthex, there is the entrance for the men, who leave the shoes outside; the women's entrance is on the west side. Finally on the side there is the cemetery and the school.

The interior is richly decorated and the floors are covered in carpet so that the faithful can easily kneel. The "mirhab" is small and is surmounted by a semi-dome forming together the "sancta sanctorum" of the mosque. The "minbar" is the pulpit of the mosque and is located on the west side of the Prayer Hall. Both elements are made of marble and enriched with geometric decoration.

Figure 5. Photo of the interior of the Pertev Pasha Mosque by Chiara Cusolito

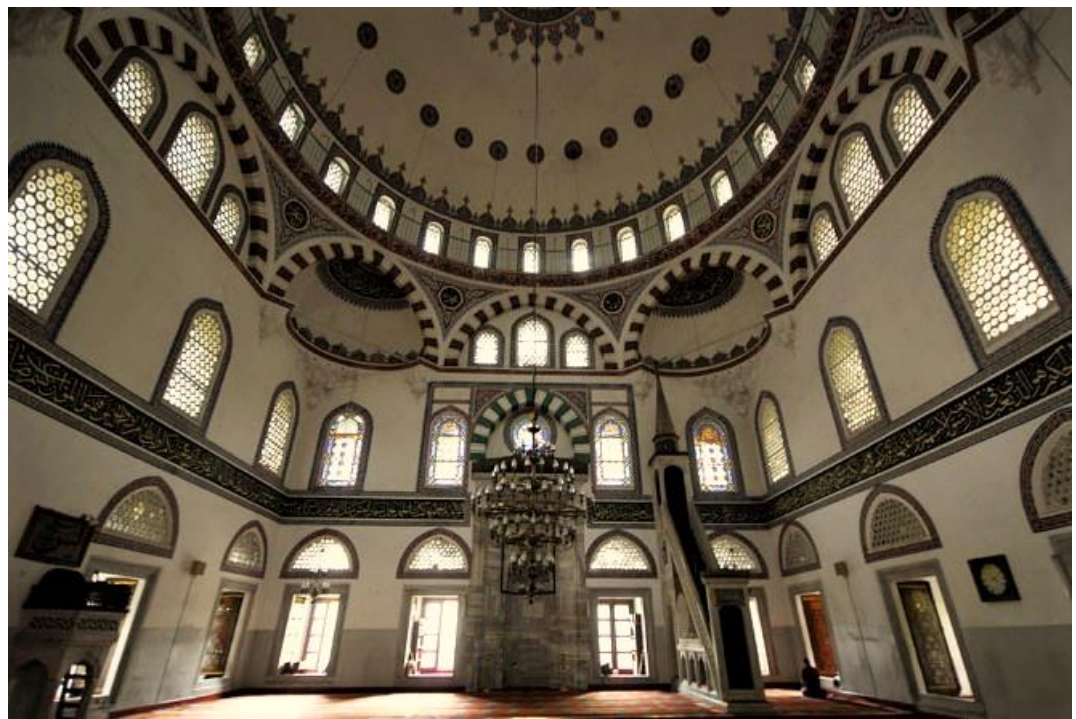

Knowledge of the mosque was acquired began through necessary historical research that allowed us to understand the social and cultural value that the mosque represents for Izmit, as well as the type of construction, the workers of the time, the additions and intervention has been successful until today. This research ended with a decisive confusion with Dr. Neslihan T. Bayraktar, Assist. Prof. Dr. Architect - Physical Environmental Control of the University of Kocaeli.

When the historical surveys were finished we started the direct survey the aim of which was a complete knowledge of the artifact. The survey is divided into two parts: the acquisition phase, during the workshop in which he provided the geometric, material, structural and functional data of the asset and the graphic representation phase of all the information in our possession.

The survey has thus enabled the deepening of the materials, of the constructive techniques and has allowed us to understand and evaluate the statics of the building and the possible presence of 
structural instability, as well as any superficial degradation pathologies in progress.

\section{History}

The foundations of the mosque were laid in 1572 but the complex was only completed in 1579 . The stages along the commercial road traveled by caravanserai that connected Anatolia to the Ottoman capital, known as the Silk Road. The mosque, given its social-religious function, rises in the city center along the commercial street, at the time flanked by the sea The mosque did not only carry out the function of a place of prayer but also a social one and indeed, the complex was enlarged and included a Turkish bath, a fountain, a caravanserai, an elementary school and a refectory for travelers and poor people.

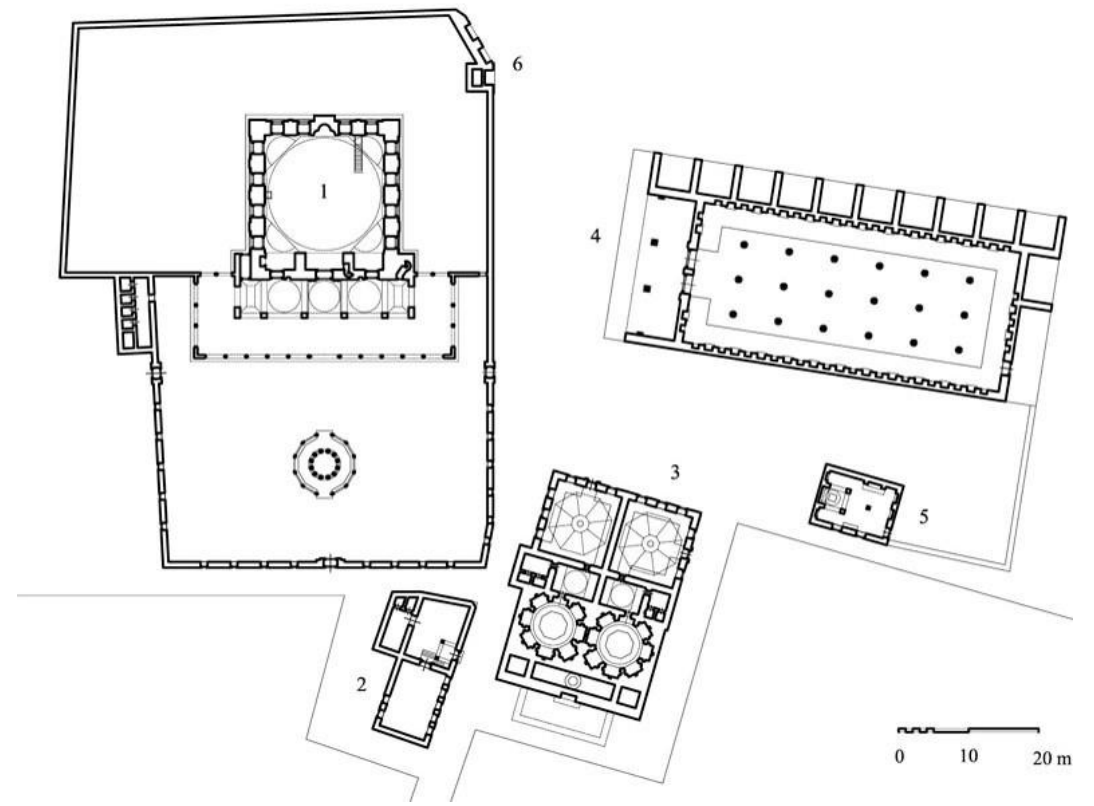

The Turkish bath, of which some remains are visible today, was located in the north-western part of the mosque, the school to the east and the caravanserai was lost completely during the earthquakes in the southwestern part.

In the Republican period, during the rearrangement of Kocaeli, with the construction plans of the first Hermann Yansen, and later under Prof. Kemal Ahmet Aru, the surroundings of the social complex were restored, and this group of structures regained its magnificent appearance.

The school has been rebuilt several times following the same constructive scheme, but thus constitutes a historical forgery. Although the complex has not been preserved in its entirety, the mosque is one of the witnesses of Ottoman architecture, in which all innovations and experiments of the architect Sinan, are to be
Figure 6. Monumental complex Pertev Mehmet Pasha:

- 1 Pertev Pasha Mosque

- 2 Elementary School

- 3 Turkish Bath

- 4 Caravanserai

- 5 Refectory

- 6 Fountain 
found furthermore, despite the passing of numerous centuries since its construction, it performs its religious and social functions perfectly, and is a point of reference for those loyal of Izmit.

\section{Geometric Survey}

The goal of geometric relief is a scale representation of the building which is the object of study in its complexity, to detect the geometry of the building and its parts as well any dissymmetry, irregularities and unevenness present, advancing hypotheses to justify any anomalies of form.

Before the investigation phase the existing graphic works dating back to the restoration after the earthquake of 1999, were provided by Prof. Emre Kishali. Based on the information received, we verified geometric measurements and any integration information missing or not sufficient. Unfortunately, it was not possible to access some areas of the Mosque which were reserved exclusively for the Imam.

In order to translate the geometry of the artifact into conventional symbols a representation scale of 1:50 and the ISO standards for drawings have been adopted. The plant is almost a perfect square, the waste between the two walls is less than $1 \mathrm{~m}$ over 22 meters in length. The plant is symmetrical with respect to the east-west axis, while it is asymmetrical compared to the north-south axis, due to the presence of the Narthex.

The dome has a diameter of 20 meters and rests of the wall with a thickness of $1.8 \mathrm{~m}$ and height of $12 \mathrm{~m}$. The entire mosque, including the drum and the dome, is $28 \mathrm{~m}$ high, while the minaret of a square plan reaches $38 \mathrm{~m}$. The walls that close the prayer hall have eight openings on each side, while on the drum there are 12 openings along the entire circumference. Moreover, there are no significant differences in the plan and the presence of architectural barriers that prevent access to the main hall have not been detected.

Figure 7. Ground floor plan of the

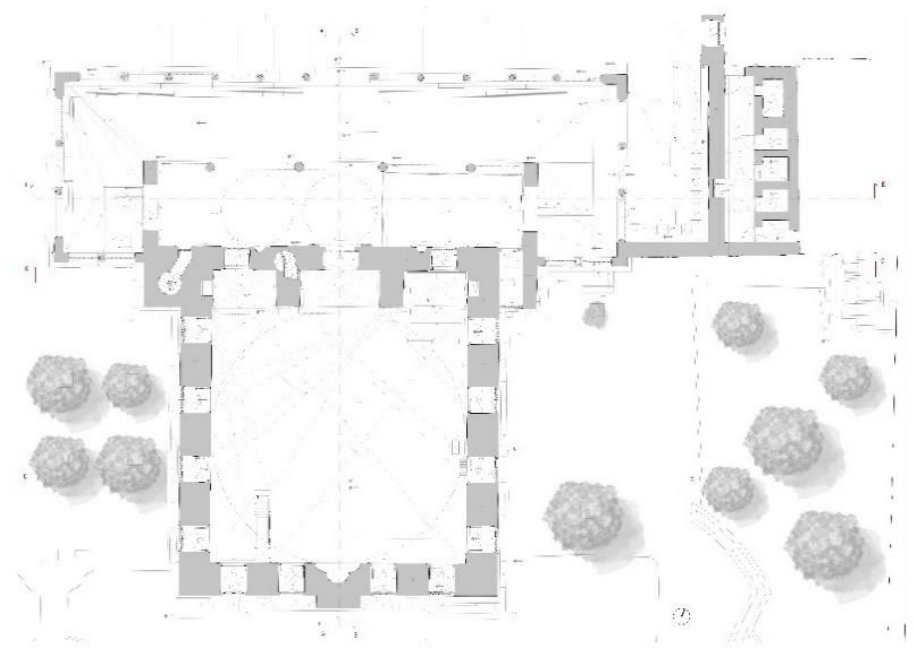




\section{Material Survey}

The mosque is almost entirely composed of tufa blocks. The roofs are covered in lead and the windows and doors are made of wood. The survey of the materials was carried out by way a visual analysis, supported by a photographic survey and a historical survey of the materials used.

At the same time, some local professionals ${ }^{4}$ who took part in the workshop conducted an invasive and non-invasive diagnostic investigation that allowed us to understand the structural static behavior of the mosque.

It has been observed that the use of tufa and marble, as materials for construction is widespread in the geographical areas near the Marmara Sea. On the other hand, the use of plaster as decoration is atypical and is covered often with ceramic tiles. The interiors are covered in plaster based on richly decorated cement mortar. This plaster does not show degradation because it dates back to the last restoration of 2001, so it is not original. In fact, the interior of the mosque was originally, contrary to Islamic custom, i.e. simply decorated with the natural stone of the masonry. The type of plaster used presents problems of incompatibility with the substrate, generating phenomena of water stagnation in the wall parameter during at a first visual inspection. Surveys of an invasive type showed that the dome is made of brick and there are cavities that improve the internal acoustics. The surveys have also affected the foundations which appear to be in blocks having a thickness and width greater proportionally to the depth which reaches sea level.

\section{Structural Analysis}

From the diagnostic investigation it appears that the stone still has an excellent compressive strength. The total thickness of the masonry is $180 \mathrm{~cm}$ and is divided into 3 layers and is not sack masonry. Finally, it is well strengthened in the cantons where there are even larger stones. The stone used is the tuff, typical of the region and in this case taken from the quarry of Astor $40 \mathrm{~km}$ away. The excess mass and the box-like behavior, almost antiseismic, allowed the mosque to survive the earthquake of 1999, which destroyed the rest of the city.
4Engineer Mehmet Selim Ökten; Arch Bahadır Bodza; Prof. Dr. Gül Köksal; Prof. Dr. Emre Kishali 
Figure 8. Mosque Pertev Pasha after earthquake of 1999

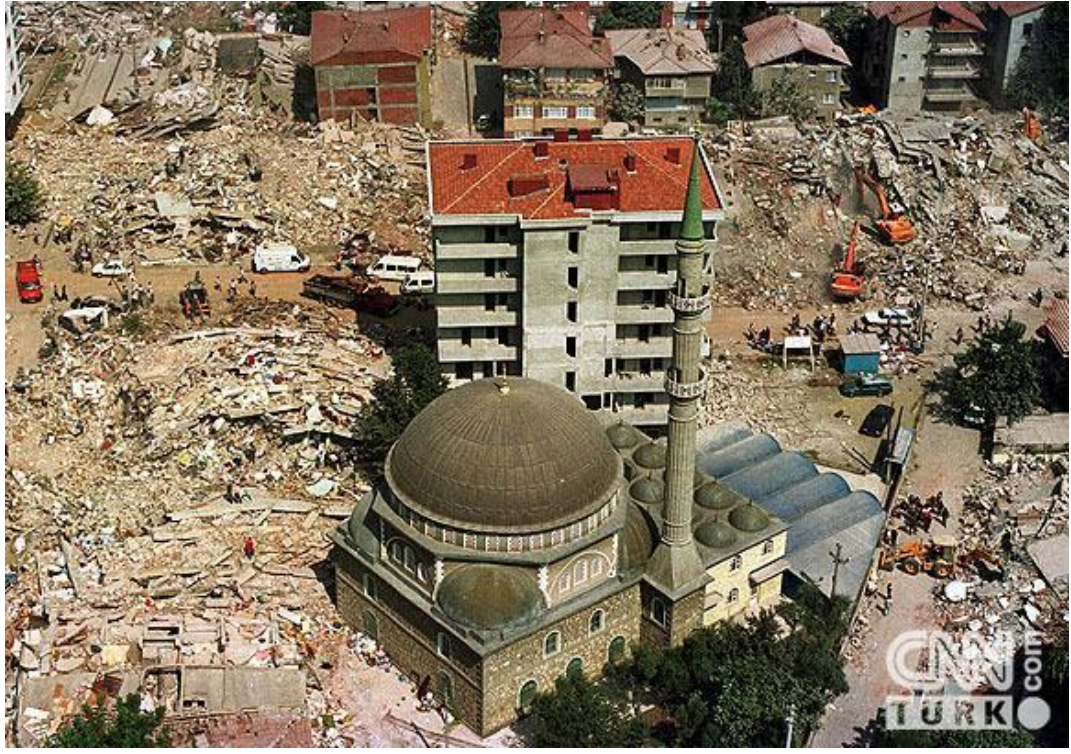

The mosque has not suffered major damage, except for a lesion on the south wall at the height of the window. There are no dangerous situations and metallic chains were introduced in the side domes replacing the wooden ring of the dome with one in steel. However, the entire surface of the tuff is affected by microcracks and superficial disintegration.

Following the data collected during the diagnostic campaign Eng. Mehmet Selim Ökten and Prof. Emre Kishali decided to create a model of the finite element mosque using the SAP 2000 program in order to verify the static and dynamic behavior of the mosque, subjecting it to the stresses of its own weight and horizontal forces, as during the earthquake, in the $\mathrm{x}$ and $\mathrm{y}$ directions (E.Kishali,2015).

The sap model has been of great help to us in understanding the static response of the artefact and has, therefore, constituted the starting point of the consolidation project.

The model shows that the structure responds very well to vertical loads, while it has a very small shear stress located near the drum at the existing crack. 


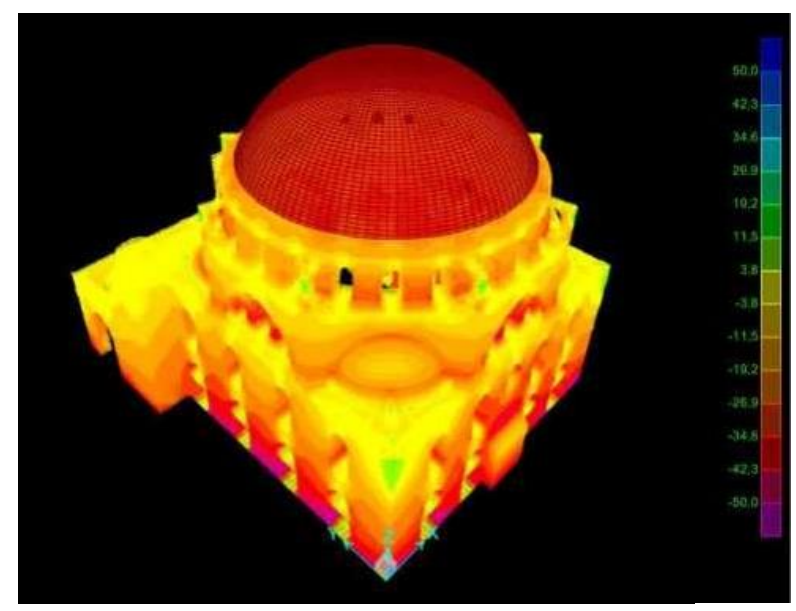

Figure 9. Static analysis, vertical loads. Sap model realized by Engineer Mehmet Selim Ökten

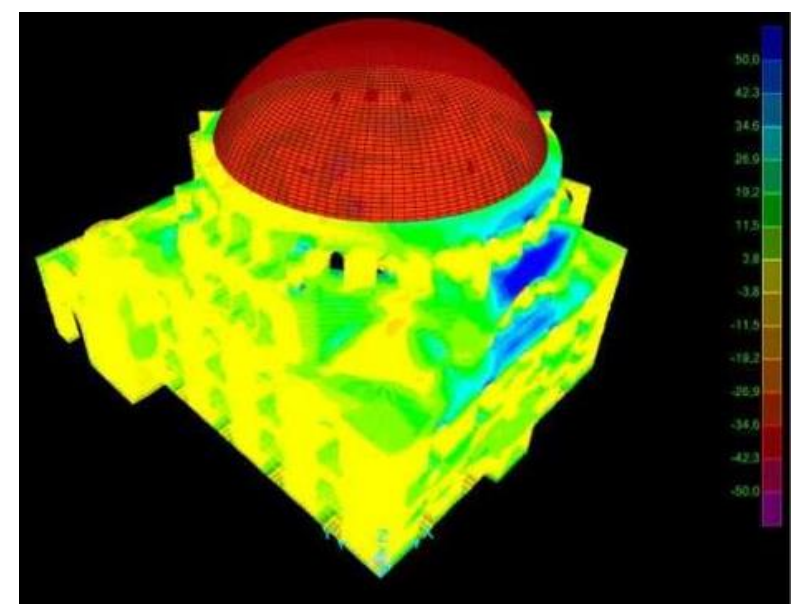

It is also noted that the masonry on the south side, once again, results to work with less compression homogeneity, presenting localized points of cut near the windows. Comparing it with the compression values of the north side where they are homogeneous on the whole surface, it can be deduced that this structural imbalance is due to the presence of the Narthex on the north side which compensates for the thrust of the dome. The dome simulations, on the other hand, show that the whole surface works with compression and there does not appear to be breaking mechanisms in the central part. The dome is very similar in both directions, presenting higher values of compression near the key and traction on the supports.

The structural analyses carried out there are no existing mechanisms, a consolidation proposal has been suggested, consistent with the principles of minimum structural intervention which aims at the global improvement of the seismic response of the structure. The first phase of the intervention involves the replacement of existing metal elements, i.e. the chains of the side domes that support the vault and the metal ring that circles the dome, eliminating any corrosion of the chains that reduces the mechanical characteristics of the element. In spite of the presence

Figure 10. Solicitations of the earthquake along the y axis sap model realized by Engineer Mehmet Selim Ökten 
of those elements, a reinforcing hypothesis is envisaged consisting in the application of high-tenacity carbon fiber, unidirectional fabrics and bidirectional fabric extrados of the test vaults, solidified to the structure by means of an epoxy adhesive. Furthermore, a series of anchors with flap openings of CFRP fabrics are used which are useful for structural connection showing a predominantly elastic linear behavior until collapse.

\section{Exterior Damage Survey}

The survey of the deterioration has pointed out that the walls are mainly affected by the presence of soluble salts both outside and inside. This is due to the mineralogical composition of the tuff and its high porosity which makes it a particularly sensitive to water (De Gennaro, 1991). The most widespread pathologies of the elevations reported are also the most dangerous for the structural and visual integrity of the masonry. This is often affected by a chromatic alteration which is both wide, diffuse and punctual (Laurenzi Tabasso, Agostino Bureca e Giorgio Palandri, 1987). Looking closely at the surface a different kind of chromatic alteration can be seen: in the lower parts of the mosque. It has a greater blackening due to the combination of IT being dissolved in exhaust gas and weathering; in the upper parts, instead, they act almost exclusively the degrading action of atmospheric agents. Moreover, the external masonry is weakened by the presence of circular cavities. These cavities are sometimes quite deep and seem to be interconnected; they have an irregular pattern on the surface and are more present in the parts most exposed to wind. In some places the phenomenon has degenerated until disintegration and pulverization of the stone in some parts of the wall element have occurred. On all the elevations, it is easy to notice the presence of white efflorescence, which can even reach a few centimeters. It is very likely that the crystals are also within the wall parameter. The saline sub-efflorescence is very dangerous because the migration of the internal crystals outwards during the cycles of freezing and thawing causes the appearance of alveoli on the stone, altering the surface of the product. They can be formed either inside the wall parameter (sub-efflorescence) or on its surface according to the saline solution flow rate with respect to the rate of evaporation at any time and at every point (G.Rocchi, 1990). The presence of black crusts has been observed in areas protected from water run off and heavy rain. The patina covering the stone appears dark in color, variable in thickness, irregular in shape, compact and anchored to the substrate. This type of deterioration alters the surface of the mosque and increases the risk of possible damage due to the effect of thermal variations until it causes phenomena of disintegration, erosion and alveolarization. In fact, in the parts 
where the deposits have become detached, due to the different thermal expansion, a disrupted and deteriorated stone surface can be seen. In the parts of the surface exposed to the action of water and wind, the loss of a superficial layer of material can be noticed. The stone is eroded and visibly damaged and the surface is not homogeneous. Other types of deterioration can be seen around the eroded surface, such as disintegration and scaling. The erosion is more extensive in correspondence of dark colored crusts due to the different thermal expansion. Finally, at the height of the base there is the presence of fungi, molds and vegetation.

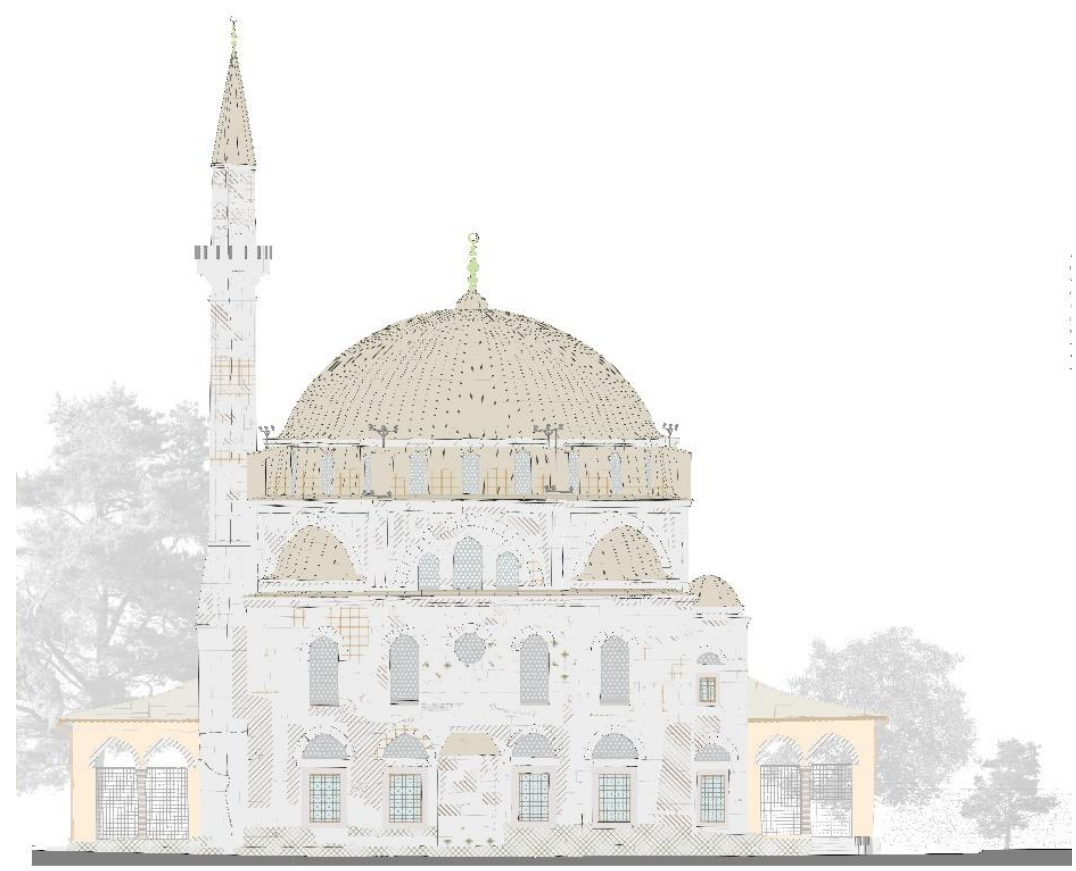

Through the use of thermography in internal environments, it has been found that the internal plaster appears well adherent to the masonry even if it has some localized detachment. Below the vaults of the mezzanine, made of stone and squared with regular blocks, different temperatures are detected, which may be the result of the presence of moisture and interstitial condensation.
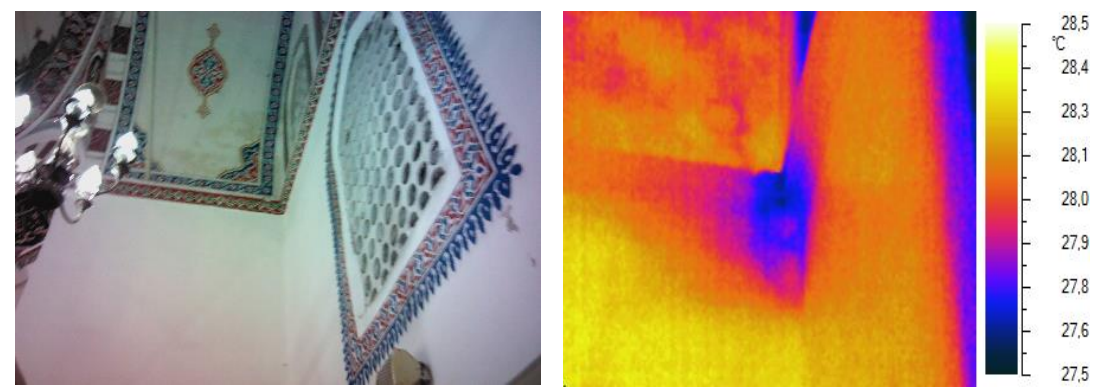

Figure 11. Survey of degradation, south-east prospect

Figure 12. Corner brickwork and mezzanine vault 
Externally, on the other hand, the mortar restoration to restore the cohesion of the masonry in the joints of previous intervention could be observe, an infiltration located in correspondence of the rainwater to the left of the north-east prospect and ensure that the masonry, by orographic conformation of the ground and for constructive and morphological characteristics, it is not subject to rising damp.

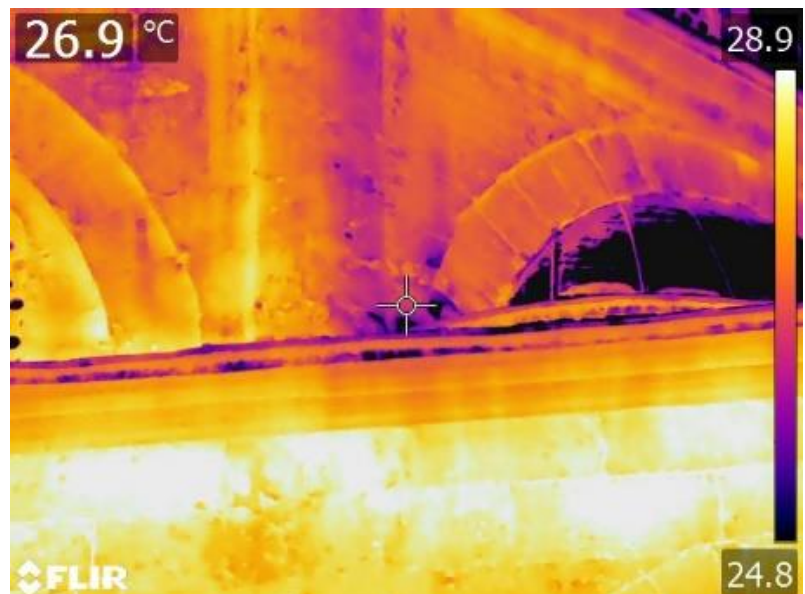

Figure 13. From this photo you can see the different materials used on the side domes, thanks to the different emissivity factor. The presence of mineral salts below the cornice is evident and presence of water in the wall

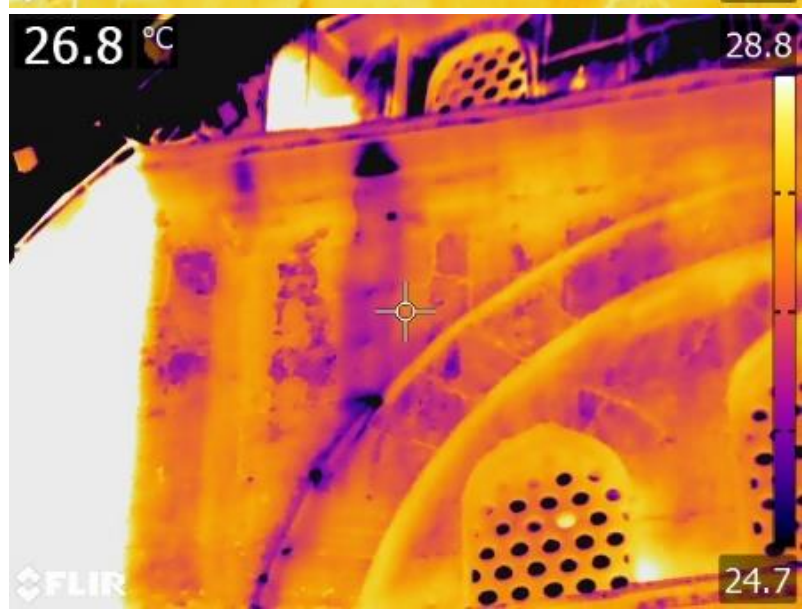

To recover the microclimate inside the mosque, data logger, temperature-humidity probes have been installed. that are able to measure temperature, humidity and air dew point with the daily. The probes were placed, one on the south side and one on the north side. Finally, a third was set up to measure the difference in temperature and humidity between the inside and outside of the mosque.

In conclusion to this analysis it is possible to affirm that the probes have detected considerable humidity inside the environment so the causes of the degradation affecting these environments are due to humidity, to the lack of control of the microclimate by means of heating systems, dehumidification and refrigeration. They also detected a strong temperature range that facilitates the rapid evaporation of the water due to infiltration and this causes 
the appearance of soluble mineral salts. The area that turns out to be the hottest and, therefore, requiring more maintenance and control is the dome.

\section{Proposed Interventions}

The definition of the intervention practices to eliminate the pathologies of degradation, cannot avoid the investigation of the causes of the same. The modalities and the speed at which the degradation phenomena occur are regulated by a high number of factors, for example the physical characteristics of the material (mechanical resistance, porosity, water absorption capacity and others) which in turn are related to mineralogical and petrographic ones, the shape and location of the artefact, the state of conservation, the distribution of stresses, and so on. In reality, this study presents many difficulties as the causes of alteration are numerous and often act concomitantly. Nevertheless, the causes are divided into active and passive factors.

The intervention proposal involved both the internal and external tables. In fact, the removal of plaster has been proposed because it is incompatible and breathable barrier which facilitates the formation of condensation.

To remedy this situation, we propose:

- verification and replacement of rainwater removal systems;

- removal of internal plaster on the walls and in the intrados of the dome;

- internal humidity control natural ventilation.

The use of decoration is common in the mosque and sentences of the Koran are depicted on the walls, we are aware that the removal of the existing plaster implies the loss of decorative elements, so we suggest the creation of new breathable plaster using structural plaster in order to increase resistance mechanics to the masonry.

Therefore, the intervention will develop according to the following steps:

- preparation of the support;

- cortical consolidation of the support if necessary mechanically weak and floured, by impregnation;

- possible regeneration of the masonry, by means of the technique of "cuci o scuci" or "rincocciatura";

- drawing up of the first rough coat;

- creation of armed "structural" plaster. In case of replacement of the same, a structural plaster based on pozzolana lime is proposed, compatible with the tuff. 
Please note that all interventions reflect the criteria of conservative restoration, such as minimal intervention and reversibility.

For external surfaces, on the other hand, interventions can be summarized as follows:

- removal of macro florescence (especially on the south side of the mosque);

- pre-consolidation of parts that are more disrupted;

- cleaning and removal of degradation;

- removal of the mineral salts present in the masonry;

- biocide treatment;

- consolidation treatment;

- water repellent treatment.

As restoration work must, therefore, be carefully planned in order to avoid damaging the materials during the operating phase, an intervention sheet has been prepared for each individual intervention, which operators and restorers must consult at the time of the work. Within these cards, the information and indications concerning the operative protocol to be followed must be listed (ICOMOS,2014).

\section{CONCLUSIONS}

The widely recognized concept of "integrated conservation" at a global level (UNESCO, ICOMOS, ICCROM, Council of Europe, etc.), highlights all the individual values united in their complexity and protected in their unity-identity in unicum that constitutes urban value. Urban value which is often subject to "risk", that is all that the city could lose in the case of a natural catastrophe, not excluding any other risks to urban settlements of ancient origin which are subject, e.g. to environmental factors such as pollution, or anthropogenic ones, tourist flow or heavy migratory flows.

Today, urban value is particularly protected compared with respect to the past where on the country it was directed exclusively towards architectural heritage. In Turkey the process of valorisation of the historical centres began after the Amsterdam Declaration of 1975.

The 1975 "Amsterdam Declaration" states that the conservation of architectural heritage must be "one of the main objectives of urban and regional planning." Support warmly " the promotion of methods, techniques and skills for restoration and rehabilitation". The identification of new methods of use for goods, involve the exercise of active protection, defined through project reuse and 
adaptation, also for tourism and cultural purposes (ICOMOS,1999).

In the international context the following "International Charter for the preservation of historic cities "written in Toledo in 1987 and ratified in the same year in Washington sets out for the first time the specific urban value of centres of ancient construction and their long historical, artistic and environmental tradition as well as the possibility that "preventive measures" would be taken to safeguard their heritage, ensuring first of all the protection of authenticity (ICOMOS, 1986-87). Europe today is characterised by a cultural diversity and thus by the plurality of fundamental values related to mobile, immobile and intellectual heritage, the different meanings associated with it and consequently also conflicts of interest. This obliges all those responsible for safeguarding cultural heritage to become increasingly attentive to the problems and choices they need to face in pursuing their objectives. Each community, by means of its collective memory and consciousness of its past, is responsible for the identification as well as the management of its heritage. Individual elements of this culural inheritance are bearers of many values which may change in time (Krakow,2000). The identity and authenticity of a city rediscovers urban value. These values are the result of an often two thousand year historical stratification and a long cultural continuity.

The concept of urban value is intrinsic with the time and its the place in history, architecture, urban spaces (walls and doors, streets and squares, market areas etc .) and all cultural heritage materials. Urban value, however, is also full of intangible values such as cultural significance, urban identity, historical importance, authenticity and social interaction (UNESCO,2003).

International instruments are meant to safeguard historical cities "the measures necessary both for their protection and their protection conservation and restoration, rather than their coherent development and their harmonious adaptation to contemporary life "( ICOMOS, 1986-87) .

\section{REFERENCES}

Cesare Brandi, (2000) "La Teoria del Restauro", Piccola Biblioteca Einaudi, ISBN 978-88-06-15565-0

De' Gennaro e Fuscaldo, (1991), "Il degrado del tufo giallo napoletano: prime osservazioni sui fenomeni di degrado dei materiali tufacei usati come pietra da costruzione" in L'ambiente geologico della Campania, A.Vallaro, ed. CUEN.

Emre Kishali, Neslihan Turkmenoglu Bayrak, (2015) https://www.researchgate.net/project/Non-Destructive- 
Test-Applications-In-the-Context-of-Planned-

Conservation-Through-Historical-Mosques-of-Kocaeli-

Coban-Mustafa-Pasa-Mosque-Fevziye-Mosque-and-

Pertev-Pasa-Mosque.

Emre Kishali, Elisabetta Rosina, Neslihan Turkmenoglu Bayrak, Alessia Silvetti, (2016) https://www.researchgate.net/pu blication/291519379_Izmit_icin_Uluslararasi_Koruma_Ya klasimi_IDEAs_Calistayi.

Giuseppe Rocchi, (1990) "Istituzioni di restauro dei beni architettonici e ambientali: cause, accertamenti, diagnosi, prevenzione, interventi, collaudi", ed. Hoepli.

ISBN 8820317974,9788820317973

ICOMOS, (1965) International charter for the conservation and restoration of monuments and sites, "The Venice Charter " article 1, IInd International Congress of Architects and Technicians of Historic Monuments, Venice 1964

ICOMOS, (Toledo 1986-Washington 1987), "Charter for the conservation of historic towns and urban areas", Adopted by ICOMOS General Assembly in Washington, DC, October 1987.

ICOMOS, (1999) International Cultural Tourism Charter, Managing Tourism at Places of Heritage Significance, Adopted by ICOMOS at the $12^{\text {th }}$ General Assembly in Mexico, October 1999.

ICOMOS, (2014) ISCARSAH Guidelines, 2014. https://iscarsah.files.wordpress.com/2014/11.iscarsahguidelines.pdf

Jean Paul Roux, (2010) "Storia dei turchi", Lecce, Argo ed.

Krakow (2000), The Charter of Krakow 2000 - "Principles for Conservation and Restoration of Built Heritage".

Oleg Grabar, (1985) "An Annual on Islamic Art and Architecture" Volume 3, E.J. Brill. ISBN 9004076115,9789004076112

Paolo De Silvestri, (2012) "Il Michelangelo d'oriente. La vita e le opere di Mimar Sinan", in Instoria n.50 Febbraio 2012 (LXXXI).

Teresa Colletta, (2005) "Il valore urbano".

The Declaration of Amsterdam, (1975) Congress on the European Architectural heritage, 21-25 October.

UNESCO, (2003) "The value of the intangible Cultural heritage", Yamato Declaration 2004.

Worksett Roy, (1970), "The Character of Towns. An Approach to Conservation”, The Architectural Press. Hardcover April, 1969.

William Curtis, (1989) “Contemporary Transformations of Modern Architecture", in Architectural Record, N.Y. 


\section{Resume}

Chiara Cusolito was born in Italy. She is graduated in Architectural Engineering at Polytechnic of Milan in Lecco. She is a Security Coordinator in the design and execution phase on construction sites in Milan.

Laura Di Marino was born in Italy. She is a Tutor of Restoration class at the School of Building Architecture and Engineering at Polytechnic of Milan in Lecco. She is an Engineer specialized in energy efficiency and building renovation.

Alessia Silvetti is an adjunct professor of Conservation Studio at the international Master Architectural Engineering Polytechnic of Milan in Lecco, and adjunct professor of Restoration Studio at the School of Building Architecture and Engineering, Polytechnic of Milan in Lecco. She has been Tutor (2009-2016) of Restoration + studio classes at the School of Building Architecture and Engineering, and Tutor (2012-2016) of Conservation + studio classes at the international Master Architectural Engineering and Polytechnic of Milan in Lecco. She's received "Tangram of Architecture 2004" in an Italian National Competition. She's interested in intervention of conservation and her focus on the historical buildings and visual quality assessment in landscape architecture. She's a member of National Bioarchitecture Institute section of Lecco. 